\title{
Sobre a Educação Ambiental e a arte de viver: por uma refundação ética e epistêmica
}

\author{
Sobre la Educación Ambiental y el arte de vivir: por una refundación ética \\ y epistémica
}

About Environmental Education and the art of living: by an ethical and epistemic refoundation

\author{
Filipi Vieira Amorim ${ }^{1}$ \\ Júlia Guimarães Neves ${ }^{2}$ \\ Alana das Neves Pedruzzi ${ }^{3}$ \\ Tamires Lopes Podewils ${ }^{4}$ \\ Felipe da Silva Justo ${ }^{5}$
}

\begin{abstract}
Resumo
O artigo, que em termos metodológicos identifica-se por sua natureza teórica, apresenta uma proposição inicial sobre a necessidade de uma inversão axiológica no campo das pesquisas que versam sobre os Fundamentos da Educação Ambiental. Parte-se do princípio de que o cuidado de si precede o cuidado com o outro, seja este outro humano ou não humano. Assim, a prerrogativa que justifica a tendência ambientalista da preservação de uma natureza supostamente não humana passa a ser criticada, momento em que emerge o reconhecimento da arte de viver como possível fundamento para a Educação Ambiental. O texto apresentado não tem a pretensão de fixarse como verdade última, mas intenta ensaiar uma reflexão sobre o problema contemporâneo que se convencionou chamar de crise ambiental e coloca à educação o desafio de responder às questões desta contemporaneidade, entre eles, as auguras da convivência humana no Planeta. Espera-se que este breve texto possa contribuir com outros desdobramentos investigativos no campo dos Fundamentos da Educação Ambiental.
\end{abstract}

Palavras-Chave: Arte de viver; Educação Ambiental; Fundamentos.

\section{Resumen}

El artículo, que en términos metodológicos se identifica por su naturaleza teórica, presenta una proposición inicial sobre la necesidad de una inversión axiológica en el campo de las investigaciones que versan sobre los Fundamentos de la Educación Ambiental. Se parte del principio de que el cuidado de sí precede el cuidado con el otro, sea este otro humano o no humano. Así, la prerrogativa que justifica la tendencia ambientalista de la preservación de una naturaleza supuestamente no humana pasa a ser criticada, momento en que emerge el reconocimiento del arte de vivir como posible fundamento para la Educación Ambiental. El texto presentado no

\footnotetext{
${ }^{1}$ Doutor em Educação Ambiental (PPGEA-FURG); Professor na Universidade Federal de Pelotas - UFPEL; Pelotas, Rio Grande do Sul, Brasil. E-mail: filipi_amorim@yahoo.com.br.

${ }^{2}$ Doutoranda em Educação; Bolsista da CAPES; Universidade Federal de Pelotas - UFPEL; Pelotas, Rio Grande do Sul, Brasil. E-mail: juliaaneves@ hotmail.com.

${ }^{3}$ Doutoranda em Educação Ambiental; Bolsista da CAPES; Universidade Federal do Rio Grande - FURG, Rio Grande, Rio Grande do Sul, Brasil. E-mail: alanadnp@gmail.com.

${ }^{4}$ Doutoranda em Educação Ambiental; Bolsista do CNPq; Universidade Federal do Rio Grande - FURG, Rio Grande, Rio Grande do Sul, Brasil. E-mail: podewils.t@gmail.com.

${ }^{5}$ Graduando em Direito; Universidade Federal do Rio Grande - FURG, Rio Grande, Rio Grande do Sul, Brasil.

E-mail: felipe.sjusto@gmail.com.
} 
tiene la pretensión de fijarse como verdad última, sino que intenta ensayar una reflexión sobre el problema contemporáneo que se ha convenido llamar la crisis ambiental y plantea a la educación el desafío de responder a las cuestiones de esta contemporaneidad, entre ellos, las auguras de la contemporaneidad, convivencia humana en el Planeta. Se espera que este breve texto pueda contribuir con otros desdoblamientos investigativos en el campo de los Fundamentos de la Educación Ambiental.

Palabras claves: Arte de vivir; Educación ambiental; Fundamentos.

\begin{abstract}
The article, which in methodological terms is identified by its theoretical nature, presents an initial proposition on the need for an axiological inversion in the field of research that deals with the Fundamentals of Environmental Education. It is assumed that caring for oneself precedes caring for the other, whether this other human or not human. Thus, the prerogative that justifies the environmental tendency of the preservation of a supposedly non-human nature starts to be criticized, at which point the recognition of the art of living emerges as a possible foundation for Environmental Education. The text presented is not intended as a final truth, but tries to rehearse a reflection on the contemporary problem that has been called the environmental crisis and places education on the challenge of responding to contemporary issues, including the human coexistence on the planet. It is hoped that this brief text may contribute to other research developments in the field of Fundamentals of Environmental Education.
\end{abstract}

Keywords: Art of living; Environmental Education; Fundamentals.

\title{
1. Introdução
}

Trazer à baila a perene discussão acerca da arte de viver e relacioná-la ao problema contemporâneo nomeado crise ambiental significa adentrar na órbita, em geral, dos desafios emergentes deste tempo. Se, por um lado, a problemática ambiental se mostra amplamente divulgada pela mídia, de outro, os resultados efetivos de sua tratativa parecem incipientes, uma vez que o discurso apocalíptico faz medrar o pragmatismo alusivo à agonia do Planeta, ou ainda, à catástrofe, ao terror e ao medo (GARRÉ, 2015).

Neste sentido, este artigo tem como objetivo geral refletir sobre a Educação Ambiental enquanto possível resposta à demanda epocal nomeada crise ambiental. Para tanto, parte-se do princípio de que é necessária uma inversão axiológica na referida tratativa, uma vez que se tornou imperativa a lógica romantizada do cuidado e da proteção a uma suposta natureza a ser salva. Em outras palavras, busca-se revisitar os discursos naturalistas e conservacionistas que, segundo Sauvé (2005), fazem parte das correntes de Educação Ambiental ocupadas com o cuidado do ambiente - entendido como natural - pelo viés da educação.

Em termos metodológicos, abordou-se a pesquisa bibliográfica como forma de viabilizar a discussão teórica e conceitual entendida como possibilidade da construção de um conhecimento que problematiza o status quo deste campo epistemológico (GERHARDT; SILVEIRA, 2009). Ainda, cabe destacar o caráter inicial desta proposta, uma vez que nos interessam, primordialmente, as possíveis interlocuções que possam vir a contribuir com este ensaio teórico-reflexivo sobre os Fundamentos da Educação Ambiental. 


\section{A Educação Ambiental e seus Fundamentos}

Inicialmente, é necessário definir o que significa tratar de fundamentos da Educação Ambiental. Fundamentar nada mais é do que justificar as razões pelas quais se propõe, defende ou apresenta algo como verdadeiro, correto ou certo. Quando se trata de um ensaio teórico, o ato de fundamentar é, portanto, uma busca que se faz pela via da argumentação. Entretanto, no sentido acadêmico-científico do termo, fundamentar é dar cientificidade a determinados discursos, ou ainda, é apresentar justificativas e elementos comprobatórios, por vezes empíricos, acerca daquilo que se pretende conhecer. É assim que se estabelecem evidências - sejam elas indubitáveis ou não - sobre certos conhecimentos - sem significar que o indubitável seja imutável. Em outras palavras, um conhecimento tem valor enquanto tal porque é, espacialmente inserido e temporalmente delimitado, real e verdadeiro. E é assim que se estabelecem os paradigmas, ou seja, conhecimentos individuais ou coletivos, cientificamente testados e comprovados, aceitos como seguros e válidos pela comunidade acadêmica (KUHN, 1995).

Para o caso da Educação Ambiental, cerne da discussão proposta neste artigo, tratarse-á a palavra fundamento como sinônimo de justificativa, isto é, entendendo que, do ponto de vista teórico, os Fundamentos da Educação Ambiental são os argumentos, estudos e pesquisas que não apenas prescrevem o quefazer da Educação Ambiental, mas que também elucidam os sentidos que justificam este quefazer.

Historicamente, pode-se conhecer a trajetória da Educação Ambiental a partir do que Grün (1996, p. 15) denominou “ecologização das sociedades”. Segundo o autor, que trata dos “antecedentes históricos da educação ambiental”, o ano de 1945 é um dos principais marcos da "ecologização das sociedades" pelo vir à tona da consciência sobre a possível destruição do Planeta pelo ser humano. Esse ano ficou marcado pelo lançamento das bombas atômicas sobre Hiroshima e Nagasaki. Como numa sequência cronológica, Grün (1996, p. 15-21) apresenta ainda outros acontecimentos que servem como referência de impulso e atenção dada ao que se nomeou Educação Ambiental: em 1962, Rachel Carson, tornou público o desaparecimento de espécies e o problema causado por pesticidas na agricultura; em 1968, Ehrlich alertou para o exacerbado crescimento populacional nos aglomerados de civilização; em 1972, com a "Primeira Conferência das Nações Unidas sobre o Meio Ambiente", em Estocolmo, a Educação Ambiental tornou-se "assunto oficial", com desdobramento semelhante em 1975, em Belgrado - "The Belgrado Workshop on Environmental Education”; já em 1983, foi criada, pela Organização das Nações Unidas - ONU, a "Comissão Mundial para o Meio Ambiente e Desenvolvimento"; e, finalizando, Grün destaca, em 1992, a 
realização da "Conferência das Nações Unidas sobre Meio Ambiente e Desenvolvimento Sustentado".

Depois do que estabeleceu Grün, considerando que a data da publicação de sua obra é 1996, destacam-se ainda outros acontecimentos que contribuíram com o que ele chamou de "ecologização das sociedades", entre outros eventos, os seguintes: a "Convenção do Clima", em 1995, em Berlim; o Protocolo de Kyoto, em 1997, em Kyoto, Japão; a “Conferência Mundial sobre o Desenvolvimento Sustentável", em Johanesburgo, em 2002; a "Conferência de Bali”, em 2007, na Indonésia; a "Conferência de Copenhagen”, na Dinamarca, em 2009; a "Conferência do Clima da ONU", em 2011; e, para finalizar, a Rio+20, "Conferência das Nações Unidas sobre desenvolvimento Sustentável", no Rio de Janeiro, em 2012. Por certo que outros eventos e, inclusive, fenômenos naturais poderiam ser nomeados como influentes no conceito do filósofo ambiental, mas entende-se que, para fins argumentativos, esta exposição é suficiente.

Levando-se em conta, ainda, que em 1972 a "educação ambiental" figura como um dos assuntos oficiais nas reuniões de cúpula internacionais, questiona-se, diante desta série de acontecimentos, quais os sentidos, os valores e as percepções, desencadeadas a partir do processo de "ecologização das sociedades"? Com o respaldo do estudo elaborado por Sauvé (2005), observa-se que a Educação Ambiental tem uma trajetória marcadamente influenciada por aquilo que Grün denominou de "ecologização das sociedades". Disso derivam duas abordagens principais que, por um estudo cartográfico, Sauvé (2005) nomeou como "conservacionista" e "preservacionista". Segundo a autora, essas abordagens preconizam aos seres humanos o dever no sentido do cuidado, da conservação e da preservação dos chamados recursos naturais. Ainda que Sauvé (2005) aponte para outras tendências, o argumento que se desenvolverá parte da crítica às supracitadas. Eis a hipótese sobre a qual este artigo edificarse-á: se há uma "natureza" a ser conservada, preservada e cuidada por ser compreendida como recurso natural, reproduz-se a percepção antropocêntrica de que a chamada natureza, em toda a sua "gratuidade", está para o ser humano como recurso a ser explorado. Portanto, eis o paradoxo: a necessidade de "educar" para conservar, preservar e cuidar do "recurso" que, por ser entendido como "recurso", não tem um valor intrínseco, mas um valor reivindicado em nome do consumo que se processa pela instrumentalização. Ao encontro disto, Sauvé (2005, p. 20) afirma que estas percepções - "conservacionista" e preservacionista" - de Educação Ambiental apresentam "imperativos de ação": conservar, preservar e cuidar - para continuar a consumir o recurso natural. 
Nestes termos, entende-se que o processo de "ecologização das sociedades" alavancou o imperativo ético e axiológico da dualidade entre humanidade e natureza, e é daí que se reivindica a inversão axiológica como justificativa ética, epistemológica e política, aos Fundamentos da Educação Ambiental. De certo modo, reconhecem-se os avanços que pesquisas sobre a relação entre Ética e Educação Ambiental, tal como as do filósofo ambiental Mauro Grün (1996; 2007a), trouxeram ao problema da percepção dicotomizada no que se refere à relação entre humanidade e natureza, porém, julga-se necessária a inversão axiológica do reconhecimento de si mesmo como o outro a que se demanda o cuidado (RICOEUR, 2014). Portanto, para além dos sentidos de preservação, conservação e cuidado, o predicado ambiental que acompanha o substantivo educação resguarda outras possibilidades, dimensão que será investigada a seguir.

\section{A refundação Ética e Epistêmica da Educação Ambiental}

O ponto em que se quer chegar é a defesa pelo reconhecimento de que a Educação Ambiental pode ampliar as suas razões de ser, sobretudo, no sentido de auxiliar na compreensão da condição humana. Mas, para que isto seja possível, é necessária uma inversão axiológica no campo dos seus fundamentos, de modo que a dicotomia entre natureza e humanidade seja, desde a percepção humana, superada. O que está em jogo é a refundação dos próprios fundamentos, isto é, o revisitar dos fundamentos em nome da problematização ética, epistemológica e política que perpassam o campo da Educação Ambiental e fazem dela uma emergência da contemporaneidade.

Do ponto de vista filosófico, sabe-se da prevalência das visões racionalista-cartesiana e empirista-baconiana que validam a interoperabilidade mecânica da natureza (AMORIM; CALLONI, 2015) e dão legitimidade em termos de paradigma (KUHN, 1995). Neste sentido, também outros pensadores criticaram enfaticamente a preponderância do paradigma cartesiano, tais como Capra (1982), e a necessidade de se pensar uma ética com o princípio da responsabilidade humanamente, individual, e planetariamente, coletiva, proposta pelos estudos de Hans Jonas (2006) a partir de sua leitura sobre o avanço da civilização tecnológica. Inúmeros outros pensadores poderiam ser nomeados e referenciados de modo a reconhecer-se que a busca pela refundação dos fundamentos epistêmicos, éticos e políticos, extensivos aos Fundamentos da Educação Ambiental, nada tem de recente. Por exemplo, destacar-se-á uma passagem de Blaise Pascal (1948, p. 124, 125) que difere dos paradigmas racionalistacartesiano e empirista-baconiano, onde o filósofo demonstrara o paradoxo da relação entre 
seres humanos e natureza com a resposta à pergunta que é o ser humano perante a natureza? Ei-la:

\begin{abstract}
Afinal, que é o homem dentro da natureza? Nada, em relação ao infinito; tudo, em relação ao nada; um ponto intermediário entre o tudo e o nada. Infinitamente incapaz de compreender os extremos, tanto o fim das coisas quanto o seu princípio permanecem ocultos num segredo impenetrável, e é-lhe igualmente impossível ver o nada de onde saiu e o infinito que o envolve.
\end{abstract}

Observa-se que o intento pascaliano, diferente dos paradigmas hegemônicos, é a compreensão da condição humana sob o viés da existencialidade contraditória, humilde, que reconhece a pequenez humana diante da vastidão infinita do Cosmos. Esse é um exemplo de refundação e inversão axiológica, uma vez que revisita o fundamento antropocêntrico (da conservação, preservação e cuidado em nome do consumo contínuo) e o reformula na tentativa de valorizar aspectos negligenciados até então.

Ao encontro do pensamento de Pascal, por exemplo, o predicado ambiental adquire outros sentidos, tal como o da abertura humana ao reconhecimento de si como parte daquela natureza até então tida como exterior ao sujeito. Note-se, ainda, que a dicotomia entre humano (sujeito) e natureza (objeto), traz consigo a herança do pensamento de René Descartes (contemporâneo de Pascal), considerado por Grün (1996) como um dos mais influentes filósofos na construção da percepção ocidental sobre a distinção entre humanos e natureza. Logo, a refundação da Educação Ambiental não deve ser apenas epistêmica, mas também ética: "na verdade, ética e epistemologia são indissociáveis, pois não se pode separar o saber dos valores (GRÜN, 2007b, p. 187).

Diante do exposto até o momento, afirma-se que a inversão axiológica não diz respeito ao cuidado, finalisticamente falando, com uma suposta natureza externa senão com a própria existência humana. Tal como advertiu Sartre (2014), não havendo uma essência humana, reconhece-se a abertura infinita da possibilidade de transformação do humano por ele mesmo, ainda que este esteja inserido em um contexto mais amplo em termos de condicionantes. Este argumento é fundamental para que se compreenda o sentido da inversão axiológica no campo dos Fundamentos da Educação Ambiental, uma vez que o cuidado de si e a compreensão da condição humana precedem o cuidado com a natureza externa e não humana. Colocadas sob crítica e análise, conclui-se que se as tendências "conservacionista" e "preservacionista" da Educação Ambiental, tal como defendeu Sauvé (2005), têm como alicerce o imperativo da ação, ou seja, do dever ser, elas limitam a capacidade de cada sujeito dar forma a si mesmo e encontrar o sentido do seu quefazer com relação ao outro. Mantendo-se os fundamentos da 
preservação e da conservação de uma natureza romantizada e vazia de sentidos, não haverá uma Educação Ambiental efetiva.

A arte de viver, entendida como fundamento da Educação Ambiental, situa o sujeito não mais na objetividade do imperativo da ação de conservação e cuidado que ampararam a "ecologização da sociedade", tal como afirmou-se anteriormente com base em Grün (1996).

Se outrora prevaleceu o fundamento entendido como comprovação, faz-se mister que a experiência criativa e contemplativa possa romper com o que fora posto como paradigma intransponível. A arte de viver nada mais é do que a estética da existência, aquilo que Nietzsche (2015) defendera como capacidade de fazer da vida uma obra de arte, perspectiva também explorada e retomada por Foucault (2005).

\section{Considerações finais}

Por certo, este artigo não apresentou conclusões definitivas, uma vez que é um primeiro ensaio de aproximação entre a Educação Ambiental e as reflexões sobre a arte de viver. Neste momento, destacar-se-á a abertura perceptiva promovida pelo predicado ambiental, tal como mencionado no subtítulo anterior. Assim, a refundação da Educação Ambiental remete ao princípio de que cada ser humano, cada comunidade, cada grupo em particular, levando em consideração uma identidade humana em comum, reconhecendo o destino coletivo da humanidade, deve esforçar-se, individual e coletivamente, para compreender a sua individualidade e a sua qualidade de sujeito que não está além ou aquém de uma suposta natureza não humana. Esta abertura nada mais é do que a superação de uma compreensão assentada no paradigma cartesiano-baconiano da disjunção, da simplificação e do domínio pela técnica que, como consequência, reduz as possibilidades de percepção da condição humana.

Aos Fundamentos da Educação Ambiental cabe o exercício do reconhecimento de que o paradigma que hoje domina não só a produção do conhecimento, mas, extensivamente, reproduz-se no viver em sociedade, não admite a reflexão sobre a arte de viver, uma vez que (de)forma o sujeito de acordo com a normatização das condutas. Propor que o ponto de partida da Educação Ambiental seja a compreensão da condição humana é também refletir sobre a arte de viver, sobretudo na busca pelas respostas sobre o sentido da vida, que é a mesma proposição para a compreensão do ser situado no mundo, que tem em sua condição humana uma identidade comum ao Cosmos e à vida em geral. 


\section{Referências}

AMORIM, F. V.; CALLONI, H. Incidências éticas e epistemológicas de Francis Bacon na concepção da Natureza: contribuições à Educação Ambiental. Revista Sul-Americana de Filosofia e Educação, n. 24, out. 2015, p. 85-101. Disponível em:

http://periodicos.unb.br/index.php/resafe/article/view/17459/12506 Acesso em: 30 ago. 2017.

CAPRA, F. O ponto de mutação. São Paulo: Editora Cultrix, 1982.

FOUCAULT, M. História da Sexualidade 3. O cuidado de si. Rio de Janeiro: Graal, 2005.

GARRÉ, B. H. O dispositivo da Educação Ambiental: modos de constituir-se sujeito na Revista Veja. 2015. 185 f. Tese (Doutorado em Educação Ambiental) - Universidade Federal do Rio Grande, Rio Grande. 2015.

GERHARDT, T. E.; SILVEIRA, D. T. (orgs.). Métodos de pesquisa. Porto Alegre: Editora da UFRGS, 2009.

GRÜN, M. Ética e educação ambiental: a conexão necessária. Campinas: Papirus, 1996.

GRÜN, M. Em busca da dimensão ética da educação ambiental. Campinas: Papirus, 2007a.

GRÜN, M. A pesquisa em ética na educação ambiental. Pesquisa em Educação Ambiental (UFSCar), v. 2, p. 185-205, 2007b.

JONAS, H. O princípio responsabilidade: ensaio de uma ética para a civilização tecnológica. Rio de Janeiro: Contraponto, 2006.

KUHN, T. A estrutura das revoluções científicas. São Paulo: Perspectiva, 1996.

NIETZSCHE, F. Schopenhauer educador. Rio de Janeiro: Editora Escala, 2015.

PASCAL, B. O homem perante a natureza. São Paulo: W. M. Jackson INC., 1948.

RICOEUR, P. O si-mesmo como outro. São Paulo: Editora WMF Martins Fontes, 2014.

SARTRE, J.-P. O existencialismo é um humanismo. Petrópolis: Editora Vozes, 2014.

SAUVÉ, L. Uma cartografia das correntes em educação ambiental. In: SATO, M.;

CARVALHO, I. C. M. (orgs.). Educação Ambiental: pesquisa e desafios. Porto Alegre:

Artmed, 2005. 